\title{
FIGHTING OBESITY CAMPAIGN IN TURKEY: EVALUATION OF MEDIA CAMPAIGN EFFICACY
}

\author{
İnci Arıkan ${ }^{1}$, Kağan Karakaya², Mustafa Erata², Hakan Tüzün², Emine Baran², Levent Göçmen², Harika Kökalan Yeşil| \\ ${ }^{1}$ Department of Public Health, Medicine Faculty, Dumlupinar University, Kutahya, Turkey \\ 2Department of Health Promotion, General Directorate of Health Promotion, Ministry of Health of Turkey, Ankara, Turkey
}

\section{SUMMARY}

Aim: This study aims to determine the frequency of behaviour change and related factors generated in the population through the "Fighting Obesity Campaign" of the Turkish Ministry of Health.

Methods: Twelve statistical regions from NUTS-1 and 18 provinces were selected for the study sample. At least one province from each region was randomly selected, and strata were defined as urban or rural. Of the sample selected, 2,038 respondents completed a face-to-face survey. Logistic regression analysis was used to analyse the data. Changing behaviour as result of the campaign was defined as the dependent variable. Behaviour change was defined as an individual taking at least one action to increase physical activity, calculate her/his Body Mass Index (BMI) or minimise meal portions.

Results: Of the sample selected, $84 \%$ of participants lived in urban areas. Of total sample selected, $49.8 \%$ were men and $50.2 \%$ were women. According to BMl categorisation, $41.4 \%$ of participants were underweight or normal weight, $34.3 \%$ were overweight and $24.3 \%$ were obese. Of the total participants, $85.2 \%$ learned about the "Fighting-Obesity Campaign" through television, $28.1 \%$ through radio, $11.0 \%$ from newspapers, $6.0 \%$ from billboards, and $19.2 \%$ from other sources. This study revealed that $28.5 \%$ of the participants adopted desired behavioural changes after exposure to the campaign. Logistic regression results demonstrated that behaviour change is greater among women, individuals living in urban settings, group of persons approving public spots, obese individuals, and among the 20-39 age group.

Conclusion: Media campaigns may cause behavioural changes by increasing motivation to prevent obesity within the target population. Continuing these campaigns can lead to success at the national level.

Key words: obesity, media campaigns, evaluation, healthy behaviour

Address for correspondence: I. Arıkan, Department of Public Health, Medicine Faculty, Dumlupinar University, 43100 Kutahya, Turkey. E-mail: iciarikan@hotmail.com

\section{INTRODUCTION}

Since the second half of the 20th century, obesity prevalence has become a growing health problem due to changes in diet and lifestyle. It was reported that there are over 500 million obese individuals and approximately 1.4 billion overweight individuals around the world, and this prevalence is expected to reach 700 million and 2.3 billion, respectively, by the year $2015(1,2)$.

Obesity places individuals into a high risk group of cardiovascular diseases by causing hypertension, diabetes and atherosclerosis and subsequent higher risk of developing cancer and musculoskeletal system diseases (2). Due to the rise in obesity, increased health-related expenses and increased health problems are expected outcomes (3).

Governments are continuously searching for solutions to mitigate this situation and creating action plans to combat an obesity epidemic that threatens health worldwide (4-8). However, the fact that environmental, genetic and behavioural factors contribute to the incidence of obesity makes preventing obesity and related health effects a challenge. In addition to promoting healthy diet and increasing physical activity, the World Health Organization (WHO) recommends that governments support their action plans with culturally appropriate media campaigns (9-11). Health risks could be reduced and behavioural changes aiming at healthy weight could be achieved through such media campaigns. The main objectives of these campaigns are to promote healthy behaviours and motivate people to modify unhealthy behaviours and adopt desired behavioural changes $(12,13)$.

Within Turkey, obesity prevalence is $20.5 \%$ among males and $41 \%$ among females, contributing to a total prevalence of $30.3 \%$ in the country. Through the prevention of obesity on national level, experts suggest that it is possible to avert $13.3 \%$ of all deaths and $7.3 \%$ of Disability Adjusted Life Years (DALYs) (14).

Turkey aims to create public action to promote health and quality of life and to reduce the obesity prevalence by $10 \%$ by 2020 . To this end, a 5-year action plan covering the years 2010-2014 was produced, and a nationwide "Fighting Obesity and Control Programme" was implemented by the Ministry of Health of Turkey (15). Within the framework of this programme, the "Fighting Obesity Campaign" (FOC) was initiated. Through FOC, obesity awareness programmes were adopted by healthcare organisations and introduced by the national media. The goal of this study is to identify the social effects of FOC.

\section{MATERIALS AND METHODS}

\section{Study Design}

The population of Turkey is approximately 74.7 million. The population above the age of 15 is 55.8 million and comprises 
$74.7 \%$ of the total population. Of the population above the age of $15,71.8 \%$ live in urban areas and $28.2 \%$ live in rural areas (16). As a candidate country to the European Union, Turkey uses the Nomenclature of Territorial Units for Statistics (NUTS). NUTS comprised 3 levels of Territorial Units of Statistics; 12 were defined as Level 1, 26 as Level 2, and 81 as Level 3 (17).

The data collection stage of the research was performed between August and September 2012. A multi-stage stratified sampling method was used. A total of 18 provinces were randomly selected, including at least one province from each of the 12 statistical regions positioned in NUTS Level 1. Settlement areas with a population of more than 20,000 were defined as urban and areas with a population less than 20,000 were defined as rural regions. Rural/urban variables were defined as the strata of the study. Neighbourhoods or villages were defined as cluster variables, and households were selected from each defined cluster. Household participation in the study was defined as an interview with at least one individual aged 15 or older.

Sample size was calculated as 2,300 with a $95 \%$ confidence interval, $2 \%$ margin of error, and $\mathrm{p}=0.50$. Face-to-face interviews were conducted with 2,323 people. Of the 2,323 participants, 2,038 participants $(87.7 \%)$ remembered the campaign and were included in the data assessments.

\section{Survey Instruments}

A questionnaire was administered after oral consent had been obtained from the participants. The questionnaire comprised three sections: the first section contained questions about socio-demographic characteristics; the second section contained questions about public media spots and whether they were wellheard, appreciated, and affected the listener; and the third section included questions about participants' level of knowledge and awareness of obesity (LKAO).

LKAO was assessed by a total of 15 survey items. Two survey items assessed participant's knowledge of the causes of obesity, 6 survey items assessed knowledge of preventative measures, and 7 items assessed participant's perceptions of the effects of obesity on society. Statements of participants were evaluated using a Likert scale. Points attributed included the following: strongly agree: 5, agree: 4, not sure: 3 , disagree: 2 , and strongly disagree: 1 . The highest score possible was 75 , and the lowest 15 . The scores were divided into two clusters by K-Means clustering analysis. These clusters were used as a reference, the scores obtained were assessed by Roc Analysis, and cut-off values were calculated.

Adopting the desired post-campaign behavioural changes was defined as a participant reporting that he or she adopted at least one protective behaviour such as increasing physical activity, learning to calculate BMI, or reducing meal portions.

BMI was calculated according to participants' reported height and weight and was evaluated with $\mathrm{Z}$ score charts based on $\mathrm{BMI}$ recommendations from $\mathrm{WHO}$ for men and women aged 15-19 years. Individuals below -2 standard deviations (SD) from standard charts were classified as underweight, individuals ranging from $-2 \mathrm{SD}$ to $+1 \mathrm{SD}$ were classified as normal, individuals between +1 SS and +2 SS were classified as overweight, and individuals above $+2 \mathrm{SS}$ were classified as obese (18). Other participants were classified as $18.5-24.9 \mathrm{~kg} / \mathrm{m}^{2}$ : normal, $25.0-29.9$ $\mathrm{kg} / \mathrm{m}^{2}$ : overweight, and $\geq 30.0 \mathrm{~kg} / \mathrm{m}^{2}$ : obese (19).

\section{Statistical Analysis}

Data were analysed with SPSS (version 15.0) and Minitab (version 15.0) Statistical Software Packs. K-Means and Roc analysis were used to establish a LKAO score cut-off value. Logistic regression analysis was used to analyse the data. The dependent variable was defined as adopting desired post-campaign behavioural changes. Age, sex, level of education, employment, level of income, place of settlement, BMI classification, positive response to the public media spots, and LKAO were established as the independent variables.

In univariate analysis, variables with $\mathrm{p}<0.10$ value were considered potential predictors in the model. Odds ratios with $95 \%$ confidence intervals were calculated from the coefficients. Values of $\mathrm{p}<0.05$ were considered statistically significant.

\section{RESULTS}

\section{Demography}

Of the participants, $84 \%$ lived in urban areas and $16 \%$ in rural areas; 1,014 (49.8\%) were male, and 1,024 (50.2\%) female; and the average age was $37.13 \pm 14.27$ ( $\min -\max 15-82)$. Of these participants, $10.1 \%$ were below the age of $20,24.2 \%$ aged $20-29$, $25.5 \%$ aged $30-39,18.1 \%$ aged $40-49,14.4 \%$ aged $50-59$ years, and $7.7 \%$ were 60 years old or older. Of the study group, $2.7 \%$ (55) were illiterate, and $4.6 \%$ (93) were unemployed. Using BMI, as calculated from participant self-report, $4.1 \%$ of participants were underweight, $37.3 \%$ were normal weight, $34.3 \%$ were overweight, and $24.3 \%$ were obese or morbidly obese (Table 1 ).

\section{LKAO Assessment}

The LKAO score was $62.18 \pm 10.51$ (min-max 15-75). The LKAO instrument's sensitivity was $70 \%$, its specificity was $58 \%$, and its cut-off value was 56.5 (ROC under curve-AUC 0.703 , $\mathrm{p}<0.001)$. Individuals who scored below 56.5 points were evaluated as having insufficient knowledge $(23.6 \%)$.

\section{FOC Awareness}

Of the 2,323 people included in the study, 2,038 (87.7\%) people reported hearing about FOC. Among 285 people (12.7\%) who did not hear about the campaign, there were no differences in socio-demographic characteristics such as age, sex, place of settlement, occupation, and education $(\mathrm{p}<0.05)$.

Within the sample, $85.2 \%$ of participants reported receiving information about the FOC through TV ads (public media spots), $28.1 \%$ through radio ads (public spots), $11.0 \%$ from newspapers, $10.8 \%$ from family and/or friends, $6 \%$ from billboards, and $8.4 \%$ from the internet and other sources (Fig. 1).

Of the participants, $28.5 \%$ (580) reported desired behavioural changes. The logistic regression model demonstrated that females and the 20-39 age group reported significant changes in behaviour, while level of education and occupation were not found to be statistically significant. Living in urban areas and being overweight or obese based on BMI significantly increased the prevalence of behavioural change. It was established to be 2.42 times higher in the group that appreciated the public spots 
Table 1. Socio-demographic characteristics of participants

\begin{tabular}{|c|c|c|}
\hline \multirow{2}{*}{ Variables } & \multicolumn{2}{|c|}{ Prevalence } \\
\hline & $\mathrm{n}$ & $\%$ \\
\hline \multicolumn{3}{|l|}{ Sex } \\
\hline Male & 1,015 & 49.8 \\
\hline Female & 1,023 & 50.2 \\
\hline \multicolumn{3}{|l|}{ Age } \\
\hline$<20$ & 205 & 10.1 \\
\hline $20-29$ & 493 & 24.2 \\
\hline $30-39$ & 520 & 25.5 \\
\hline $40-49$ & 369 & 18.1 \\
\hline $50-59$ & 294 & 14.4 \\
\hline$\geq 60$ & 157 & 7.7 \\
\hline \multicolumn{3}{|c|}{ Level of education } \\
\hline Illiterate & 55 & 2.7 \\
\hline Primary & 1,134 & 55.6 \\
\hline Secondary & 566 & 27.8 \\
\hline High school & 283 & 13.9 \\
\hline \multicolumn{3}{|l|}{ Employment } \\
\hline Unemployed & 93 & 4.6 \\
\hline Full-time job & 804 & 39.5 \\
\hline Part-time job & 94 & 4.6 \\
\hline Housewife & 642 & 31.5 \\
\hline Retired & 212 & 10.4 \\
\hline Student & 287 & 14.1 \\
\hline \multicolumn{3}{|l|}{ Living area } \\
\hline Rural & 326 & 16.0 \\
\hline Urban & 1,712 & 84.0 \\
\hline \multicolumn{3}{|l|}{ BMI } \\
\hline Underweight & 84 & 4.1 \\
\hline Normal & 760 & 37.3 \\
\hline Overweight & 699 & 34.3 \\
\hline Obese & 495 & 24.3 \\
\hline
\end{tabular}

and 2.17 times higher in individuals with a sufficient amount of information (Table 2).

\section{DISCUSSION}

In the 2008-2013 Action Plan for the Global Strategy for the Prevention and Control of Non-communicable Diseases established by WHO, countries were encouraged to fight preventable risk factors for non-communicable diseases (20).

Turkey also followed the global steps defined in the action plan and implemented programmes for reducing tobacco use, unhealthy diet, and physical inactivity (15). The Ministry of Health initiated a new structuring process by "Project of Transformation in Health" and the health promotion activities used in such programmes have been re-arranged. Turkish law requires the Ministry of Health to prepare programmes (public media spots) on health and preven- tion that are especially cautionary, informative, and instructive and to broadcast them.

Such regulations contributed to Turkey's success in fighting the harmful health effects of tobacco according to the guidelines established by WHO (21). Following current regulations, attention was focused on obesity prevention projects through FOC to create awareness about obesity, its causes and prevention. For the purposes of improving health and conveying accurate information to society, cooperation with the media was established. Within the scope of the campaign, public media spots stressed the message about the importance of physical activity. These media spots included information about BMI, how BMI can be calculated, that a BMI of above 25 means a person is overweight and that healthy diet and eating small portions would help to maintain a healthy weight.

Numerous studies illustrate that campaigns promoted by the media constitute the foundation of many society-based prevention programmes and that such campaigns can reach large audiences $(22,23)$.

A 1-day TV campaign titled "Heart for Life" in Norway reached $90 \%$ of the target population, mass media campaign targeting the reduction of oil purchase in the Netherlands reached $60 \%$ of society, and the "Fighting Fat, Fighting Fit" campaign implemented in Britain that included the main message of maintaining a healthy diet and increasing physical activity for obesity prevention was heard by more than the half of the target population (24-26).

The fact that in our study, a vast majority of the participants $(87.7 \%)$ reported that they had heard of the campaign demonstrates that the campaign's message reached a large section of the population. There were no differences in socio-demographic characteristics between participants who heard the campaign and participants who were unaware of the campaign, indicating that the study was unbiased. However, as evaluating the impact on different strata of the population, results are presented for adjusted models including relevant socio-demographic characteristics (age, sex, living areas).

Television generated a large share of the awareness of the campaign, emphasising its importance as a media channel for health promotion, e.g. campaign messages of the Obesity Prevention Media Campaign targeted at Mexican Americans appeared primarily in TV morning show segments (27).

Public media spots were broadcasted through national channels for approximately 3 minutes per day for 3 months. The fact that

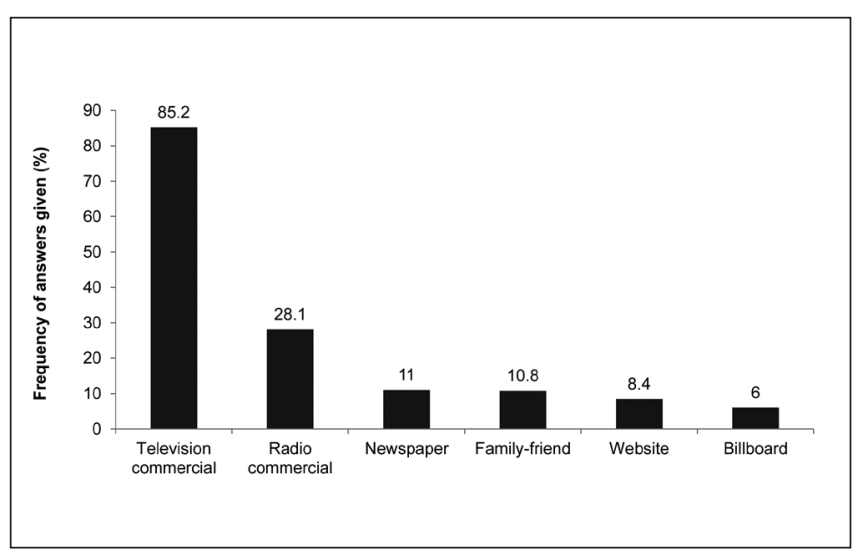

Fig. 1. Sources from people heard FOC. 
Table 2. Odds ratio and $95 \%$ confidence interval by factors related to the prevalence of behaviour change after FOC

\begin{tabular}{|c|c|c|c|}
\hline \multirow[b]{2}{*}{ Variables } & \multicolumn{3}{|c|}{ Group providing the desired behaviour change } \\
\hline & $\begin{array}{c}\text { Prevalence } \\
\%\end{array}$ & $\begin{array}{c}\text { Crude OR } \\
(95 \% \mathrm{Cl})\end{array}$ & $\begin{array}{c}\text { Adjusted OR } \\
(95 \% \mathrm{Cl})^{\mathrm{a}}\end{array}$ \\
\hline \multicolumn{4}{|l|}{ Sex } \\
\hline Male & 24.9 & 1 & 1 \\
\hline Female & 32.1 & $1.41(1.16-1.72)^{*}$ & $1.56(1.17-2.09)^{*}$ \\
\hline \multicolumn{4}{|l|}{ Age } \\
\hline$<20$ & 15.4 & 1 & 1 \\
\hline $20-39$ & 30.8 & $1.18(0.84-2.66)$ & $1.28(1.08-3.12)^{* *}$ \\
\hline $40-59$ & 28.6 & $1.17(0.89-1.81)$ & $1.25(0.97-2.29)$ \\
\hline$\geq 60$ & 24.2 & $0.94(0.58-1.52)$ & $1.15(0.89-2.08)$ \\
\hline \multicolumn{4}{|c|}{ Level of education } \\
\hline Illiterate & 20.0 & 1 & 1 \\
\hline Primary & 29.3 & $1.65(0.83-3.24)$ & $1.77(0.86-3.65)$ \\
\hline Secondary & 26.5 & $1.44(0.74-2.86)$ & $1.71(0.81-3.63)$ \\
\hline High school & 30.7 & $1.88(0.91-3.62)$ & $2.01(0.91-3.52)$ \\
\hline \multicolumn{4}{|l|}{ Employment } \\
\hline Unemployed & 20.4 & 1 & 1 \\
\hline Full-time job & 28.9 & $1.27(0.71-2.28)$ & $1.35(0.93-2.68)$ \\
\hline Part-time job & 24.5 & $1.09(0.53-2.25)$ & $1.19(0.63-2.51)$ \\
\hline Housewife & 33.3 & $1.38(0.79-2.42)$ & $1.39(0.77-2.52)$ \\
\hline Retired & 26.4 & $1.31(0.72-2.61)$ & $1.41(0.75-2.73)$ \\
\hline Student & 22.0 & $0.93(0.48-1.77)$ & $0.98(0.61-1.94)$ \\
\hline \multicolumn{4}{|l|}{ BMI } \\
\hline Normal & 16.9 & 1 & 1 \\
\hline Overweight & 33.5 & $2.46(1.94-3.13)^{*}$ & $2.29(1.76-2.86)^{*}$ \\
\hline Obese & 41.0 & $3.40(2.64-4.34)^{*}$ & $3.11(2.34-4.04)^{*}$ \\
\hline \multicolumn{4}{|l|}{ Living area } \\
\hline Rural & 18.4 & 1 & 1 \\
\hline Urban & 30.4 & $1.93(1.43-2.62)^{* *}$ & $1.61(1.17-2.20)^{* *}$ \\
\hline \multicolumn{4}{|c|}{ Status of liking public spots } \\
\hline No & 15.5 & 1 & 1 \\
\hline Yes & 30.5 & $2.40(1.70-3.37)^{*}$ & $2.42(1.71-3.45)^{*}$ \\
\hline \multicolumn{4}{|l|}{ LKAO } \\
\hline Insufficiently & 17.0 & 1 & 1 \\
\hline Sufficiently & 36.7 & $2.83(2.18-3.12)^{*}$ & $2.17(1.73-2.72)^{*}$ \\
\hline
\end{tabular}

${ }^{\mathrm{a} A g e}$, sex and living areas variables were adjusted.

${ }^{*} \mathrm{p}<0.001 ;{ }^{* *} \mathrm{p}<0.01$

$86.7 \%$ of participants liked the ads and that behavioural change increased in this group is related to the fact that television is found in almost all households and thus plays an important role in conveying messages about health. However, although conveying the desired messages to a large section of society and audiences remembering these messages are primary steps for attaining a healthy lifestyle, they may not be sufficient in establishing behavioural changes (23).

In the "Fighting Fat, Fighting Fit" campaign implemented in Britain, $30 \%$ of participants remembered healthy lifestyle messages, but less than $1 \%$ consulted authorities to adopt the recommended behavioural changes (26). Similarly, the campaign implemented in the Netherlands did not have sufficient strength to establish behavioural changes in individuals (25).

In our study, $52 \%$ of the group remembered the primary message, and $28.5 \%$ adopted at least one behaviour such as BMI calculation, downsizing portions, and increasing physical activity in line with the messages promoted. However, one of the limitations of the study is that the results were based on the personal statements of individuals and not on measurable values. Increasing physical activity and downsizing portions as behavioural changes leads to prevention or fighting obesity but calculating her/his BMI may not. However, calculating his/her BMI may raised the subject's awareness of his/her level of obesity.

The fact that about one fourth of participants reported that they established desired behavioural changes suggests that the campaign made an impression nationwide and motivated people to change.

The fact that obese groups exhibited a rate of behaviour change that was 3 times higher compared to other groups demonstrates that the campaign messages successfully reached the target population. In line with previous field study results and the "Health Belief Model", females reported a greater number of behavioural changes than males, including behavioural changes such as increased physical activity and dieting for the purpose of losing weight (26-29). Because of the results of previous studies, high behavioural changes in females were anticipated. Similar results were found in the "Obesity Day" campaign implemented in northern Italy (30).

The literature illustrates that young people can embrace changes in health behaviour more easily than older people. This creates an advantage for intervention studies. In our study, for example, we anticipated an increased number of behavioural changes in the 20-39 age group because of age close to younger population.

Due to higher socio-economic status, technologic advancements and accompanying sedentary lifestyle, obesity has increased precipitously in urban areas $(31,32)$.

However, amenities used for weight control such as sports fields and professionals such as dieticians are more accessible in urban areas. In these areas, individuals value physical appearance and being fit as a means of gaining acceptance in work, life, and society. People living in urban areas are more exposed to billboards, posters and campaign materials.

The literature suggests that increasing general knowledge and awareness of potential health risks are the primary steps in preventing the spread of diseases such as obesity (33).

Many studies report that improving individuals' knowledge of risk factors leads to success in fighting obesity $(14,34-36)$.

In our study, the fact that we found behavioural changes two times higher in individuals with a sufficient amount of knowledge about obesity supports this theory. Knowledge about obesity increased the adoption of desired behavioural changes. However, a comparative outcome cannot be presented because we do not have any data on participants' level of knowledge before the campaign; this is the limitation of the study.

A majority of the target population heard about this national campaign by watching FOC TV ads, and many remembered the main messages conveyed about obesity awareness. The fact that there were no differences among participants regarding education 
level, employment, income level, or provision of behavioural change suggests that the campaign addressed all strata of society.

However, it is important to note that the campaign had a lower success rate in changing behaviour among males, individuals in advanced age groups, non-obese individuals, individuals living in rural areas, and individuals with insufficient knowledge. These groups may need additional preventive services for obesity.

\section{CONCLUSION}

Increasing obesity awareness in groups with fewer behavioural changes and continuing campaigns such as FOC will also increase nationwide success. Data obtained in this study will be used to create a guide for methodology to be adopted in later stages of the campaign and to target the campaign at the specific groups. Public media spots in various formats and other communications that provide evocative messages at certain intervals in the year will continue as the campaign progresses.

The $28 \%$ behavioural change that this campaign attained will contribute to reaching the desired society profile in the future.

\section{Conflict of Interests}

None declared

\section{REFERENCES}

1. World Health Organization. Media centre. Obesity and overweight. Fact sheet no. 311 [Internet]. Geneva: WHO [updated 2014 Aug; cited 2014 Sep 4]. Available from: http://www.who.int/mediacentre/factsheets/fs311/ en/index.html.

2. Diet, nutrition and the prevention of chronic diseases: report of a joint WHO/FAO expert consultation, Geneva, 28 January - 1 February 2002. WHO technical report series 916. Geneva: WHO; 2003.

3. Au N, Marsden G, Mortimer D, Lorgelly PK. The cost-effectiveness of shopping to a predetermined grocery list to reduce overweight and obesity. Nutr Diabetes. 2013 Jun 24;3:e77. doi: 10.1038/nutd.2013.18.

4. U.S. Department of Health and Human Services. The Surgeon General's call to action to prevent and decrease overweight and obesity. Rockville (MD): U.S. Department of Health and Human Services, Public Health Service, Office of the Surgeon General; 2001.

5. The New Jersey obesity prevention action plan. Trenton (NJ): New Jersey Department of Health and Senior Services; 2006.

6. National Obesity Taskforce. Healthy weight 2008: Australia's future: the national action agenda for children and young people and their families. Canberra: Department of Health and Ageing; 2003.

7. National action plan against obesity: recommendations and perspectives: short version. Copenhagen: National Board of Health, Center for Health Promotion and Prevention; 2003.

8. New Zealand, Ministry of Health. Healthy action, healthy eating: towards and integrated approach to physical activity, nutrition and healthy weight for New Zealand: a draft for consultation Oranga Kai-Oranga Pumau. Wellington: Ministry of Health; 2002.

9. Wakefield MA, Loken B, Hornik RC. Use of mass media campaigns to change health behaviour. Lancet. 2010 Oct 9;376(9748):1261-71.

10. Nichols MS, Swinburn BA. Selection of priority groups for obesity prevention: current approaches and development of an evidence-informed framework. Obes Rev. 2010 Oct;11(10):731-9.

11. Redman S, Spencer EA, Sanson-Fisher RW. The role of mass media in changing health-related behaviour: a critical appraisal of two models. Health Promot Int. 1990;5(1):85-101.

12. Evans WD, Uhrig J, Davis K, McCormack L. Efficacy methods to evaluate health communication and marketing campaigns. J Health Commun. 2009 Jun;14(4):315-30.

13. Swinburn B, Gill T, Kumanyika S. Obesity prevention: a proposed framework for translating evidence into action. Obes Rev. 2005 Feb;6(1):23-33.
14. Bora Başara B, Güler C, Yentür GK, Pulgat E, editors. Health statistics yearbook 2011. Ankara: Republic of Turkey, Ministry of Health, General Directorate of Health Research; 2012.

15. Ministry of Health of Turkey, General Directorate of Primary Health Care. Obesity Prevention and Control Program of Turkey (2010-2014). Ankara: Ministry of Health of Turkey; 2010.

16. Turkish Statistical Institute. Turkey in statistics 2011. Ankara: Turkish Statistical Institute; 2012.

17. Burrell AM, Oskam AJ, editors. Turkey in the European Union: implications for agriculture, food and structural policy. Wallingford: CABI Publishing; 2005.

18. World Health Organization. Programmes. Growth reference 5-19 years [Internet]. Geneva: WHO [cited 2014 Sep 4]. Available from: http:www. who.int/growthref/who2007_bmi_for_age/en/index.html.

19. Romero-Corral A, Somers VK, Sierra-Johnson J, Thomas RJ, CollazoClavell ML, Korinek J, et al. Accuracy of body mass index in diagnosing obesity in the adult general population. Int J Obes (Lond). 2008 Jun;32(6):959-66.

20. 2008-2013 action plan for the global strategy for the prevention and control of noncommunicable diseases: prevent and control cardiovascular diseases, cancers, chronic respiratory diseases and diabetes. Geneva: WHO; 2008.

21. Inandi T, Caman OK, Aydın N, Onal AE, Kaypmaz A, Turhan E, et al. Global Health Professions Student Survey - Turkey: second-hand smoke exposure and opinions of medical students on anti-tobacco law. Cent Eur J Public Health. 2013 Sep;21(3):134-9.

22. Puhl R, Peterson JL, Luedicke J. Fighting obesity or obese persons? Public perceptions of obesity-related health messages. Int J Obes (Lond). 2013 Jun;37(6):774-82.

23. Bauman AE, Bellew B, Owen N, Vita P. Impact of an Australian mass media campaign targeting physical activity in 1998. Am J Prev Med. $2001 \mathrm{Jul} ; 21(1): 41-7$.

24. Fønnebø V, Søgaard AJ. The penetrating educational effect of a massmedia based fund-raising campaign "heart for life". Scand J Soc Med. 1990 Sep;18(3):185-93.

25. van der Feen de Lille JCJF, Riedstra M, Hardeman W, Wedel M, Brug J, Pruyn JFA, et al. Fat Watch: a nationwide campaign in The Netherlands to reduce fat intake-process evaluations. Nutr Health. 1998;12(2):107-17.

26. Wardle J, Rapoport L, Miles A, Afuape T, Duman M. Mass education for obesity prevention: the penetration of the BBC's 'Fighting Fat, Fighting Fit' campaign. Health Educ Res. 2001 Jun;16(3):343-55.

27. Reininger BM, Barroso CS, Mitchell-Bennett L, Cantu E, Fernandez ME, Gonzalez DA, et al. Process evaluation and participatory methods in an obesity-prevention media campaign for Mexican Americans. Health Promot Pract. 2010 May;11(3):347-57.

28. Bish CL, Blanck HM, Serdula MK, Marcus M, Kohl HW 3rd, Khan LK. Diet and physical activity behaviors among Americans trying to lose weight: 2000 Behavioral Risk Factor Surveillance System. Obes Res. 2005 Mar;13(3):596-607.

29. Schwarzer R. Modeling health behavior change: how to predict and modify the adoption and maintenance of health behaviors. Appl Psychol. 2008 Jan;57(1):1-29.

30. Barichella M, Malavazos AE, Fatati G, Cereda E; ADI Lombardia Study Group. Awareness and knowledge about weight status and management: results from the $1 \mathrm{~d}$ sensitization campaign 'Obesity Day' in northern Italy. Public Health Nutr. 2011 Oct;14(10):1813-22.

31. Jahns L, Baturin A, Popkin BM. Obesity, diet, and poverty: trends in the Russian transition to market economy. Eur J Clin Nutr. 2003 Oct;57(10):1295-302.

32. Pikala M, Kaleta D, Bielecki W, Maniecka-Bryła I, Drygas W, Kwaśniewska M. Awareness of cardiovascular prevention methods among residents of post-communist Polish provinces with highest mortality rates. Cent Eur J Public Health. 2011 Dec;19(4):183-9.

33. Nichols MS, Reynolds RC, Waters E, Gill T, King L, Swinburn BA, et al. Community-based efforts to prevent obesity: Australia-wide survey of projects. Health Promot J Austr. 2013 Aug;24(2):111-7.

34. Swinburn B, Wood A. Progress on obesity prevention over 20 years in Australia and New Zealand. Obes Rev. 2013 Nov;14 Suppl 2:60-8.

35. Swinburn B, Egger G. Preventive strategies against weight gain and obesity. Obes Rev. 2002 Nov;3(4):289-301.

36. Kwaśniewska M, Kaleta D, Dziankowska-Zaborszczyk E, Drygas W. Healthy behaviours, lifestyle patterns and sociodemographic determinants of the metabolic syndrome. Cent Eur J Public Health. 2009 Mar; 17(1):14-9. 